\title{
Are serum leptin levels a prognostic factor in advanced lung cancer?
}

\author{
Anar $\mathrm{C}^{1}$, Deniz $\mathrm{D}^{1}$, Erol $\mathrm{S}^{1}$, Batum $\mathrm{O}^{1}$, Bicmen $\mathrm{C}^{2}$, Yilmaz $\mathrm{U}^{1}$ \\ Izmir Dr. Suat Seren Chest Diseases and Surgery Training and Research Hospital, Department of Chest \\ Diseases, Izmir, Turkey. drceydaanar@hotmail.com
}

\begin{abstract}
AIM: The aim of the present study was to evaluate pre-treatment concentrations of leptin in patients with advanced lung cancer and to investigate possible associations between their levels and clinicopathological variables, response to therapy and overall survival.

MATERIAL AND METHODS: There are 71 previously untreated patients with cytological or histological evidence of primary lung cancer who were admitted to the oncology department between November 2013 and August 2014. Forty-five healthy individuals with age, sex and BMI matching the lung cancer patients, were recruited to take part in the study as a control group. Leptin levels were measured quantitatively by using a microELISA kit. RESULTS: The serum leptin levels at diagnosis were significantly lower in lung cancer patients than those in control subjects $(4.75 \pm 4.91 \mathrm{ng} / \mathrm{ml}, 9.67 \pm 8.02 \mathrm{ng} / \mathrm{ml} ; p<0.001)$. We did not find any significant difference in leptin values related to clinicopathological parameters such as ECOG PS, weight loss, histological type, disease stage and TNM classification. Nevertheless, we demonstrated a significant correlation between serum leptin levels and BMI in lung cancer patients (correlation coefficient: $0.303 ; p>0.010$ ). The analysis of serum leptin values did not show any association with the overall survival of the patients.

CONCLUSION: Our results showed that the serum leptin level has no prognostic indications in advanced lung cancer patients. Leptin is decreased in lung cancer, and there is lack of correlation with tumour-related factors including prognosis. Therefore, leptin is not a useful clinical marker in lung cancer (Tab. 2, Fig. 2, Ref. 22). Text in PDF www.elis.sk. KEY WORDS: leptin, survival, prognosis.
\end{abstract}

\section{Introduction}

Although lung cancer is the second most seen and most deadly cancer type in both genders, there is not any reliable marker for early diagnosis and treatment (1). Leptin, a gene-expression protein secreted mainly by adipocytes, is a pleiotropic hormone with roles of modulating weight balance, inhibiting food intake and regulating energy metabolism. Recent studies showed the importance of leptin in lung development and lung diseases like cancer (2-4). Leptin increases the inflammation and carcinogenic risk by affecting both innate and adaptive immunity (5). Studies showed that functional polymorphism in leptin and leptin receptor gene increases susceptibility for non-small cell lung cancer (NSCLC) and serum levels of leptin is high in lung cancer patients and correlates with disease stage (6-8).

The aim of the present study was to evaluate pre-treatment concentrations of leptin in patients with advanced lung cancer and to investigate possible associations between their levels and clinicopathological variables, response to therapy, and overall survival.

${ }^{1}$ Izmir Dr. Suat Seren Chest Diseases and Surgery Training and Research Hospital, Department of Chest Diseases, Izmir, Turkey, and ${ }^{2}$ Izmir Dr. Suat Seren Chest Diseases and Surgery Training and Research Hospital, Department of Microbyology, Izmir, Turkey

Address for correspondence: C. Anar, Izmir Dr. Suat Seren Chest Diseases and Surgery Training and Research Hospital, Department of Chest Diseases, Izmir, Turkey.

Phone: +90.505 .4840070$

\section{Material and method}

There are 71 previously untreated patients with cytological or histological evidence of primary lung cancer who were admitted to the oncology department between November 2013 and August 2014. Weight and height were recorded at admittance and BMI (body mass index) was calculated as $\mathrm{kg} / \mathrm{m}^{2}$. Weight loss was defined as a loss of more than $5 \%$ of pre-illness weight in the previous 3 months. All the patients were locally in advanced or advanced stages and they were treated with first-line platinum-based chemotherapy. Staging of the NSCLC patients was established by clinical findings, chest X-ray, bronchoscopy, thorax CT, brain MR and PET-CT based on the latest TNM staging system (9). We evaluated the response to therapy. To define treatment response Response Evaluation Criteria in Solid Tumors (RECIST) were used. Patients who had a partial or complete response at the end of the first-line chemotherapy were classified as responders, whereas patients who had stable disease or progression were classified as non-responders.

Forty-five healthy individuals with age, sex and BMI matching the lung cancer patients were recruited to take part in the study as a control group. Both patients and controls suffering from comorbidities that affect weight maintenance (diabetes, thyroid dysfunction, alcoholism, malabsorption, renal and hepatic disease) or lead to systemic inflammation (infection, heart failure, collagen vascular disease) were excluded from the study. The ethics committee of our hospital approved this study and all subjects provided written informed consent. 
Tab. 1. The characteristics of patients.

\begin{tabular}{|c|c|}
\hline Characteristics & $\mathrm{n}=71$ \\
\hline \multicolumn{2}{|l|}{ Age (years) } \\
\hline$\leq 65$ & $44(61.9 \%)$ \\
\hline$>65$ & $27(38.1 \%)$ \\
\hline \multicolumn{2}{|l|}{ Gender } \\
\hline Female & $4(5.6 \%)$ \\
\hline Male & $67(94.4 \%)$ \\
\hline \multicolumn{2}{|l|}{ Smoking habit } \\
\hline Smoker & $63(88.7 \%)$ \\
\hline Nonsmoker & $5(7 \%)$ \\
\hline Exsmoker & $3(4.2 \%)$ \\
\hline \multicolumn{2}{|l|}{$\overline{\text { ECOG PS }}$} \\
\hline 0 & $12(16.9 \%)$ \\
\hline 1 & $45(69 \%)$ \\
\hline 2 & $10(15.1 \%)$ \\
\hline \multicolumn{2}{|l|}{ Weight loss } \\
\hline$\leq 5 \%$ & $34(47.9 \%)$ \\
\hline$>5 \%$ & $37(52.1 \%)$ \\
\hline \multicolumn{2}{|l|}{ Histological type } \\
\hline Adenocarcinoma & $23(32.4 \%)$ \\
\hline Squamous & $20(28.2 \%)$ \\
\hline NSCLC & $13(18.3 \%)$ \\
\hline SCLC & $15(21.1 \%)$ \\
\hline \multicolumn{2}{|l|}{ Stage (NSCLC) } \\
\hline Stage $3 \mathrm{~A}$ & $8(11.3 \%)$ \\
\hline Stage $3 B$ & $16(22.5 \%)$ \\
\hline Stage 4 & $33(46.5 \%)$ \\
\hline \multicolumn{2}{|l|}{ SCLC } \\
\hline Limited & $5(7 \%)$ \\
\hline Advanced & $10(12.7 \%)$ \\
\hline \multicolumn{2}{|l|}{ TNM } \\
\hline $\mathrm{T} 1-2 / \mathrm{T} 3-4$ & $9 / 62$ \\
\hline N0-1 / N 2-3 & $7 / 64$ \\
\hline M0 / M1 & $31 / 40$ \\
\hline \multicolumn{2}{|l|}{ Response } \\
\hline Partial/ complete response & $23 / 5$ \\
\hline Stable/progression & $12 / 31$ \\
\hline
\end{tabular}

\section{Determination of serum leptin levels}

Serum samples were separated from the clotted blood by centrifugation and aliquoted for storage at $-20^{\circ} \mathrm{C}$ till the time of application process within six months. Leptin levels were measured quantitatively by using a microELISA kit (DRG Diagnostics GmbH, Marburg, Germany) on automated ETI-Max 3000 microplate analyser [DiaSorin S.p.A., Saluggia (Vercelli), Italy] in accordance with the recommendation of the manufacturer. Standards, low and high level controls were used as supplied by the manufacturer. The most precise value for each sample was calculated quantitatively $(\mathrm{ng} / \mathrm{mL})$ by using an automated and computerbased program (4 Parameter Logistics). All standards and controls were found within the acceptable validity ranges as stated by the manufacturer. Leptin values higher than $5 \mathrm{ng} / \mathrm{mL}$ were evaluated over normal reference intervals [normal population values; male: $3.84 \pm 1.79$, female: $7.36 \pm 3.73)(10)$.

\section{Statistical analysis}

Statistical analyses were performed using the SPSS Statistics (SPPS, version 20; IBM) program. Since leptin levels did not cor-

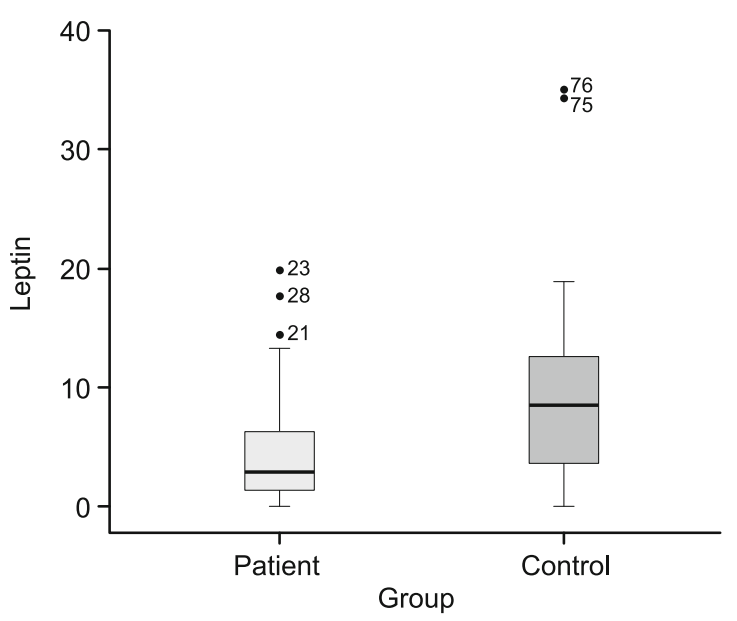

Fig. 1. Serum levels of leptin in lung cancer patients and controls.

respond to normal distribution, non-parametric tests were used. Kruskal-Wallis in multiple groups, Mann Whitney U test in binary comparisons.All data are expressed as meadian (min-max). Comparison of serum leptin levels were made using nonparametric tests like Mann-Whitney U and Kruskal-Wallis. Spearman's coefficient was used for correlations of quantitative data. Significance was defined as a value of $\mathrm{p}<0.05$.

\section{Results}

\section{Patient characteristics}

The patient characteristics are presented in Table 1. The majority of patients were elderly and predominantly male (mean age 58 years; range 38-72 years; female to male ratio $4: 67$ ). Of 71 patients with lung cancer, 56 patients were diagnosed with NSCLC (23, 20 and 13 patients had adenocarcinoma, squamous cell carcinoma (SqCLC), and non-otherwise specified (NOS) NSCLC, respectively) and 15 with small cell lung cancer (SCLC). All patients had a good Eastern Cooperative Oncology Group performance score (ECOG PS); 12 patients with $\mathrm{ECOG}=0$ and 45 with $\mathrm{ECOG}=1,10$ patients with ECOG 2. Thirty-seven patients were diagnosed with weight loss.

\section{Serum levels of leptin}

The serum leptin levels at diagnosis were significantly lower in lung cancer patients than those in control subjects $(4.75 \pm 4.91$ $\mathrm{ng} / \mathrm{ml}, 9.67 \pm 8.02 \mathrm{ng} / \mathrm{ml} ; \mathrm{p}<0.001$ ) (Fig. 1).

Leptin levels in relation to clinicopathological characteristics and response to therapy

The data of our measurements were further analysed in order to estimate any possible association with patients' clinicopathological characteristics, and summarized in Table 2. We did not find any significant difference in leptin values related to clinicopathological parameters such as ECOG PS, weight loss, histological type, disease stage and TNM classification. But there was a statistically significant difference in leptin levels in relation to BMI and age 
Tab. 2. Leptin levels in relation to clinicopathological features of the lung cancer patients.

\begin{tabular}{|c|c|c|c|}
\hline \multirow{2}{*}{$\begin{array}{l}\text { Patient } \\
\text { characteristics }\end{array}$} & \multirow{2}{*}{$\mathrm{n}$} & \multicolumn{2}{|l|}{ Leptin } \\
\hline & & Median (Min-max) & $\mathrm{p}$ \\
\hline \multicolumn{4}{|l|}{ Age } \\
\hline$\leq 65$ & 44 & $3.05(0-19.9)$ & \multirow[t]{2}{*}{$0.014^{*}$} \\
\hline$>65$ & 27 & $7.9(0-35.2)$ & \\
\hline \multicolumn{4}{|l|}{ Weight loss } \\
\hline$\leq 5 \%$ & 34 & $5.4(0-29.7)$ & \multirow[t]{2}{*}{0.713} \\
\hline$>5 \%$ & 37 & $5(0-35.2)$ & \\
\hline \multicolumn{4}{|l|}{$\overline{\mathrm{BMI}}$} \\
\hline$\leq 22.9$ & 36 & $2.7(0-35.2)$ & \multirow[t]{2}{*}{$0.010^{*}$} \\
\hline$>22.9$ & 35 & $6(0-29.7)$ & \\
\hline \multicolumn{4}{|l|}{$\overline{\text { ECOG PS }}$} \\
\hline 0 & 12 & $2.8(0-10.5)$ & \multirow{3}{*}{0.480} \\
\hline 1 & 49 & $5.5(0-35.2)$ & \\
\hline 2 & 10 & $5.9(0-14.5)$ & \\
\hline \multicolumn{4}{|l|}{ Histology } \\
\hline Adeno $\mathrm{Ca}$ & 23 & $6.7(0-35.2)$ & \multirow{4}{*}{0.727} \\
\hline SQCC & 20 & $5.1(0-17.7)$ & \\
\hline NSCLC & 13 & $3(0-12.2)$ & \\
\hline SCLC & 15 & $4.9(1-29.7)$ & \\
\hline \multicolumn{4}{|l|}{$\mathrm{T}$} \\
\hline T1-2 & 9 & $5.6(0.3-12.2)$ & \multirow[t]{2}{*}{0.346} \\
\hline $\mathrm{T} 3-4$ & 62 & $4.9(0-35.2)$ & \\
\hline \multicolumn{4}{|l|}{$\overline{\mathrm{N}}$} \\
\hline N0-1 & 7 & $1.7(0.4-35.2)$ & \multirow{2}{*}{0.293} \\
\hline $\mathrm{N} 2-3$ & 64 & $5.3(0-29.7)$ & \\
\hline \multicolumn{4}{|l|}{$\mathrm{M}$} \\
\hline M0 & 31 & $3.7(0-29.7)$ & \multirow[t]{2}{*}{0.614} \\
\hline M1 & 40 & $5.7(0-5.2)$ & \\
\hline \multicolumn{4}{|l|}{ Stage } \\
\hline IIIA/IIIB & 29 & $3.9(0-29.7)$ & \multirow[t]{2}{*}{0.907} \\
\hline IV & 45 & $5.30(0-35.2)$ & \\
\hline Response & 28 & $2.9(0-29.7)$ & \\
\hline Non response & 43 & $5.2(0-35.2)$ & 0.365 \\
\hline \multicolumn{4}{|l|}{ Survival } \\
\hline Died & 28 & $5.0(0-29.5)$ & \multirow[t]{2}{*}{0.823} \\
\hline Alive & 43 & $5.4(0-35.2)$ & \\
\hline
\end{tabular}

(Tab. 2). Although we did not find any difference in leptin levels related to weight loss, we demonstrated a significant correlation between serum leptin levels and BMI of lung cancer patients (Correlation coefficient: $0.303 ; \mathrm{p}>0.010$ ).

Additionally, there was no statistically significant difference in serum leptin levels between responders and non-responders.

Association of leptin levels and other factors with overall survival

Receiver operating characteristic curve (ROC) analysis (Fig. 2) demonstrated that serum leptin levels for lung cancer about sensitivity and specificity. The area under the curve for leptin level was $0.516(95 \%$ CI $0.376-0.656, p=0.823)$. The analysis of serum leptin values did not show any association with the overall survival of the patients. Thus, in our study we did not find a cut off value for lung cancer patients' survival.

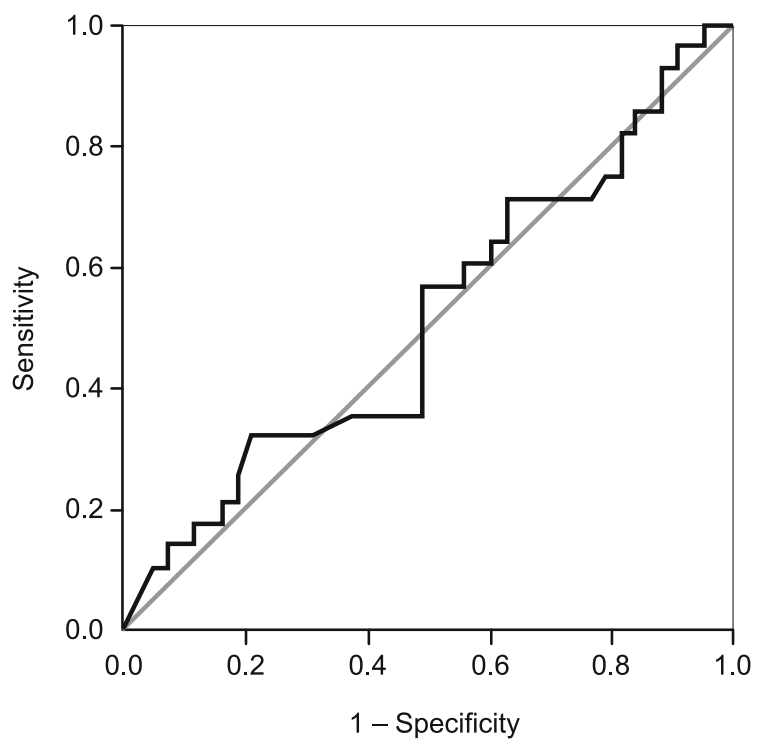

Fig. 2. Receive operating characteristics curve serum leptin levels for lung cancer. The area under the curve for leptin level was $0.516(95 \%$ CI 0.376-0.656; $\mathrm{p}=0.823$ ).

\section{Discussion}

In the present study, we demonstrated that serum levels were lower for leptin in lung cancer patients compared to controls. Also, we found that serum leptin levels may not serve as an independent prognostic factor for survival in lung cancer patients.

Regarding leptin, our finding of its decreased circulating levels in the patient group is in accordance with the majority of related studies that have found statistically significant results (11, $12,13)$. On the contrary, there are some studies with elevated levels of leptin $(7,8)$. Our study results also show that there was a correlation between BMI and leptin levels, but no correlation between stage disease and leptin levels. BMI and smoking habit affect leptin levels $(14,15)$. Moreover, the patients were distributed almost equally in advanced stages as seen in Table 1 .

In our study, serum leptin levels did not show a significant effect on the overall survival of lung cancer patients. A study demonstrated that serum leptin has prognostic indications in patients with lung adenocarcinoma who are treated with cisplatin/pemetrexed chemotherapy in the first-line setting (16). In another study, an interesting finding was that serum leptin levels showed a significant effect on the overall survival of lung cancer patients. Lower leptin levels at diagnosis were followed by shorter survival; this finding is in agreement with the results presented by Aleman et al. Study (11). The results in our study did not show that serum leptin could play a potential role as a prognostic marker in response to chemotherapy. We thought that the main reason for these results were different histopathological subgroups and chemotherapy regimens. Not only lung carcinoma, but also leptin shows a prognostic value for the overall survival rate in patients with gastric adenocarcinoma (17), hepatocellular carcinoma (18) and colorectal adenocarcinoma (19). 
Although Duru (20) et al found high serum leptin levels in advanced stage of lung NSCLC compared to healthy subjects, we did not find any correlation between serum leptin levels and lung cancer stage or histological subtype. Also, as opposed to the results of previous studies, we did not identify any statistically significant association between baseline serum levels of the leptin and response to treatment (13). These findings suggest that their levels cannot be used as predictive factors for lung cancer.

Similar with Tas et al and Kerenidi et al, we found that serum leptin levels in advanced lung cancer patients were lower compared to those in healthy subjects $(13,21)$. Although Werynska (22) et al found that cachectic patients have lower serum leptin levels, we did not find statistical correlation between weight loss and serum leptin levels. Nevertheless, in our study, we found that serum leptin concentration has been shown to be significantly lower in the cancer patients whose BMI is lower than $22.9 \mathrm{~kg} / \mathrm{m}^{2}$ and confirmed the positive leptin correlation with BMI. In both Aleman's (11) and Werynska's study (22), the higher serum leptin concentration was combined with better nutrition. The results of Aleman et al (11) who found a positive leptin correlation with such factors as BMI and body fat mass are similar to those of our study. Our findings suggest that serum leptin level was not a reliable indicator of prognosis in patients with non-small cell lung carcinoma like Tas et al. There are several limitations to our study. Firstly, our sample size was restricted to 71 patients, which is insufficient for a comprehensive analysis. Secondly, in our study, the leptin levels were not investigated after the chemotherapy. So, this was another limitation to our study. However, leptin was reduced regardless of the response to chemotherapy and did not reach a statistical significance $(p=0.06)$ in the study by Tas et al (13). In another study (16); the change in serum leptin levels were evaluated during chemotherapy. There was no statistically significant difference pre- and post-chemotherapy. There is a need to design studies specifically to elucidate the role of leptin in the molecular mechanism of lung carcinogenesis.

In conclusion, in this study we investigated the clinical significance of leptin in lung cancer. Our results showed that in serum samples, the leptin levels in the lung cancer patient group were significantly lower compared to those in the control group. Furthermore, leptin was correlated with BMI, but no correlations with other tumor-related factors was found. Current results suggest that leptin might not be an independent prognostic factor for survival.

\section{References}

1. Siegel R, Ma J, Zou Z, Jemal A. Cancer Statistics, 2014. CA Cancer J Clin 2014; 64: 9-29.

2. Malli F, Papaioannou AI, Gourgoulianis KI, Daniil Z. The role of leptin in the respiratory system: an overview. Resp Res 2010; 11: 152.

3. Meier U, Gressner AM. Endocrine regulation of energy metabolism: review of pathobiochemical and clinical chemical aspects of leptin, ghrelin, adiponectin, and resistin. Clin Chem 2004; 50 (9): 1511-1525.

4. Trayhurn P, Wood IS. Adipokines: inflammation and the pleiotropic role of white adipose tissue. Br J Nutr 2004; 92: 347-355.

5. Ribeiro R, Araujo A, Lopes C, Medeiros R. Immuno inflammatory mechanisms in lung cancer development: is leptin a mediator? J Thorac Oncol 2007; 2: 105-108.
6. Ribeiro R, Araujo AP, Coelho A, Catarino R, Pinto D, Araujo A, et al. A functional polymorphism in the promoter region of leptin gene increases susceptibility for non-small cell lung cancer. Eur J Cancer 2006; 42: 1188-1193.

7. Song CH, Liao J, Deng ZH, Zhang JY, Xue H, Li YM, Liang C et al. Is leptin a predictive factor in patients with lung cancer? Clinical Biochemistry $2014 ; 47: 230-232$.

8. Carpagnano GE, Spanevello A, Curci C, Salerno F, Palladino GP, Resta $\mathbf{O}$ et al. IL-2, TNF-alpha, and leptin: local versus systemic concentrations in NSCLC patients. Oncol Res 2007; 16: 375-381.

9. Detterbeck FC, Boffa DJ, Tanoue LT. The new lung cancer staging system. Chest 2009; 136: 260-271.

10. User's Manual. DRG Leptin (Sandwich) ELISA. DRG Instruments GmbH, Germany, vers. 9.0, 2012.

11. Aleman MR, Santolaria F, BatistaN, de La Vega M, GonzalezReimers E, Milena A et al. Leptin, role in advanced lung cancer. A mediator of the acute phase response or a marker of the status of nutrition? Cytokine 2002; 19: 21-26.

12. Jamieson NB, Brown DJ, Wallace MA, Mcmillan DC. Adiponectin and the systemic inflammatory response in weight -losing patients with non-small cell lung cancer. Cytokine 2004; 27: 90-92.

13. Tas F, Duran D, Argon A, Oguz H, Camlica H, Yasasever V, Topuz E. Serum Levels of Leptin and Proinflammatory Cytokines in AdvancedStage Non-Small Cell Lung Cancer. Med Oncol 2005; 22 (4): 353-358.

14. Mantzoros CS, Moschos S, Avramopoulos I, Kaklamani V, Liolis A, Doulgerakis DE et al. Leptin concentrations in relation to body mass index and tumour necrosis factor alpha system in humans. J Clin Endocrinol Metab 1997; 82: 3408-3413.

15. Supervva A, Enjuanees A, Villa J, Mellibovsky L, Nougts X, DvezPirez A. Effect of tabacco smoking on leptin serum levels and iis relationship with steroid hormones and bone mineral density. Med Clin 2006; 127: 645-647.

16. Mou W, Xue H, Tong H, Sun S, Zhang Z, Zhang C et al. Prognostic value of serum leptin in advanced lung adenocarcinoma patients with cisplatin/pemetrexed chemotherapy. Oncol Lett 2014; 7: 2073-2078.

17. Zhao X, Huang K, Zhu Z, Chen S, Hu R. Correlation between expression of leptin and clinicopathological features and prognosis in patients with gastric cancer. J Gastroenterol Hepatol 2007; 22: 1317-1321.

18. Wang SN, Yeh YT, Yang SF, Chai CY, Lee KT. Potential Role of leptin expression in hepatocellular carcinoma. J Clin Pathol 2006; 59; 930-934.

19. Guadagni F, Roselli M, Martini F, Spila A, Riondino S et al. Prognostic significance of serum adipokine levels in colorectal cancer patients. Anticancer Res 2009; 29: 3321-3327.

20. Duru S, Sönmez Z, Saygideğer Y, Sever Ö, Önal B, Ardiç S. The relationship between stage and tumor type and serum leptin level and leptin expression on tumor tissue in lung cancer. Tubercul Thorax 2011; 59 (4): 427-428.

21. Kerenidi T, Lada M, Tsaroucha A et al. Clinical significance of serum adipokines levels in lung cancer. Med Oncol 2013; 30: 507.

22. Werynska B, Kosacka M, Gołecki M, Jankowska R. Leptin serum levels in cachectic and non-cachectic lung cancer patients. Pneumonol Alergol Pol 2009; 77: 500-506. Accepted November 27, 2016. 